\title{
A PARTICIPAÇÃO POLÍTICA DAS MULHERES AGRICULTORAS NAS ORGANIZAÇÕES POPULARES E SINDICAIS NO SUDOESTE DO PARANÁ
}

\author{
Roselí Alves dos Santos \\ Universidade Estadual do Oeste do Paraná \\ Rua: Maringá, 1200 \\ Francisco Beltrão - PR \\ roseliasantos@gmail.com
}

RESUMO

Esta reflexão decorre das experiências e estudos a partir de um projeto de pesquisa/extensão sobre a organização política das mulheres agricultoras do sudoeste do Paraná, o qual se desenvolve com base em pesquisa bibliográfica e das entrevistas qualitativas realizadas com mulheres da região, estruturadas a partir da metodologia de Sistematização de Experiências Populares, na construção da narrativa do processo. A centralidade está na organização política a partir da constituição do Movimento Popular de Mulheres no Sudoeste do Paraná e da constituição da Comissão Sindical de Mulheres Agricultoras. A partir dessas análises apresentamos brevemente a organização e os desafios atuais.

PALAVRAS-CHAVE: mulheres, agricultura familiar, organização política.

\begin{abstract}
LA PARTICIPACIÓN POLÍTICA DE LAS MUJERES AGRICULTORAS EN LAS ORGANIZACIONES POPULARES Y SINDICALES EN EL SUROESTE DEL PARANÁ

RESUMEN

Esta reflexión es resultado de las experiencias y estudios de un proyecto de investigación/extensión sobre la organización política de las mujeres agricultoras del suroeste de Paraná, el cual se desarrolla con base en investigación bibliográfica y entrevistas cualitativas realizadas con mujeres de la región, estructuradas a partir de la metodología de Sistematización de Experiencias Populares, en la construcción de la narrativa del proceso. El trabajo se centra en la organización política a partir de la constitución del Movimiento Popular de Mujeres en el Suroeste de Paraná y de la constitución de la Comisión Sindical de Mujeres Agricultoras. A partir de esos análisis presentamos brevemente la organización y los desafíos actuales. Palabras- clave: Mujeres; Agricultura familiar; Organización política; Suroeste de Paraná.
\end{abstract}




\section{INTRODUÇÃO}

A temática da organização político e do processo de desenvolvimento a partir da perspectiva de gênero tem aumentado nos últimos anos, tanto no meio acadêmico como no seio das organizações políticas e produtivas. O debate não é novo, mas tem na sua centralidade um reporto a necessidade da equidade entre homens e mulheres. Historicamente as mulheres têm ocupado lugares de menos destaque, resultando em maior dificuldade para inserção na vida pública, sendo suas atividades na maioria dos casos restritos a vida privada domiciliar. A relação entre homens e mulheres é uma manifestação social que expressa formas de conduta social nas relações cotidianas e nos processos organizativos, muitas vezes baseados em preconceitos e discriminação, que resultam em exclusão social de homens e mulheres.

A pesquisa que realizamos parte justamente da analise dos processos destacados por mulheres agricultoras do sudoeste do Paraná em relação à invisibilidade do seu trabalho e do processo organizativo desenvolvido ao longo da história, os quais para elas são fundamentais na visão para a organização política da agricultura familiar, a qual é base identitária deste território.

O sudoeste do Paraná é efetivamente um território de base da agricultura familiar, entendida como a organização de homens e mulheres agricultores que resistem em pequenas unidades de produção de base familiar, com uso intensivo das terras como forma de garantia da manutenção da vida familiar. As dificuldades para garantir o acesso as melhores condições de vida a partir das suas pequenas unidades de produção familiar, tem exigindo um efetivo e constante processo organizativo desses sujeitos, resultando em uma forte rede de organização política manifestada em organizações cooperativas ou associativas, que constituem uma rede territorial importante e expressiva.

O resgate da organização política das mulheres agricultoras no sudoeste do Paraná faz-se necessário não só pela importância da sua participação no processo organizativo, quando não se tinha na discussão da perspectiva de gênero uma centralidade, mas pela relevância desta participação, em especial em uma sociedade patriarcal forte e que tende a não reconhecer a importância do trabalho da mulher para além das unidades domésticas. 
A construção da pesquisa apresentada é feita em parceria com entidades que fazem parte da rede organizativa política e produtiva dos agricultores do sudoeste do Paraná, como a Associação de Estudos e Orientação Rural (ASSESOAR), Sindicato de Trabalhadores Rurais de Francisco Beltrão, Instituto de Formação do Cooperativismo Solidário (INFOCOS) e Universidade Estadual do Oeste do Paraná a partir de financiamentos disponibilizados pelo Programa de Extensão Universidade Sem Fronteiras e pela Fundação Araucária, envolvendo pesquisadores e bolsistas recém formados, mestrandos e graduandos dos cursos de geografia e pedagogia participantes do Grupo de Estudos Territoriais da Unioeste (GETERR).

Os estudos sobre as diferentes formas de organização política no sudoeste do Paraná tem sido o foco dos estudos realizados por este grupo, que a compreende a relevância da temática da organização política das mulheres agricultoras a partir da compreensão da singularidade da organização política das mulheres como processo territorial, portanto cultural, político e econômico. A compreensão do processo de organização política das mulheres agricultoras como uma construção social objetiva contribuir na (des)construção de processos que estimulam as desigualdades entre homens e mulheres, sujeitos do mesmo território, com lutas e desafios comuns e singulares, mas não únicos.

\section{MULHERES E AGRICULTURA FAMILIAR}

Assim, neste texto buscamos resgatar as experiências político organizativas das mulheres no sudoeste do Paraná, ou seja, tratamos das agricultoras familiares, buscando focar e distingui-las no seio desta forma de organização: a agricultura familiar, pois muito se tem escrito sobre esta, mas raramente se distingue a mulher neste contexto.

No sudoeste do Paraná a organização das mulheres agricultoras não ocorre a partir da especificidade de ser mulher, mas como agricultora em defesa dos direitos da agricultura familiar. Isso ocorre pelo próprio contexto territorial na qual estas se inserem. Embora o Movimento Popular de Mulheres no Brasil no período pós década de 1970 represente a luta das mulheres em base feministas contra a ditadura militar, no sudoeste do Paraná este se institui muito próximo a Igreja, revelando ao longo do seu processo a limitação desta atuação. Assim, a primeira forma de institucionalização de um movimento popular de 
mulheres no sudoeste do Paraná reflete a organização socioterritorial, sendo um movimento que nasce da organização da Igreja Católica, baseada em um processo de reflexão do papel da mulher na defesa da família, embora diferentes temáticas envolvendo a condição da mulher fossem trabalhadas sob diversos aspectos como: mulher e sociedade, mulher e bíblia, mulher e sindicato etc.

Neste contexto, como a família se constitui baseada no trabalho agrícola, sua defesa é pela agricultura familiar. Assim, não se trata de uma organização de caráter feminista que critica a sua condição de mulher na agricultura familiar, mas na consistência de uma organização de reflexão e luta pelos direitos sociais e por política públicas.

Essa composição decorre das relações de poder que estão intrínsecas na organização da agricultura familiar, na qual o patriarcado é expressivo. Desta forma, a temática especifica de gênero, compreendida como a interface da diferença entre homens e mulheres expressa nas relações sociais, não assume a centralidade do debate. Um dos indicadores que demonstra esse fato é que dos 48.353 domicílios rurais do sudoeste Paranaense em 2007, segundo dados do IBGE, 85\% tem os homens como responsáveis pelos mesmos, percentual superior ao verificado no Brasil (77\%) e no Paraná (82\%).

Na tabela 01 os dados apresentados auxiliam na compreensão deste processo, pois em um território marcado pela agricultura familiar apenas 8\% destes são dirigidos por mulheres, um percentual inferior ao verificado no restante do estado e do Brasil. Um aspecto conservador também está relacionado à idade, pois aquelas com menos 35 anos representam o menor grupo e a maioria das responsáveis pela direção dos estabelecimentos está no grupo acima de 45 anos, muito provavelmente decorrente de um processo de viuvez. As jovens muitas vezes deixam o campo pela dificuldade de se inserir de forma mais autônoma nos processos produtivos e organizativos, sendo que as dificuldades de acesso à escola, trabalho físico mais penoso acaba por fomentar que as próprias mães incentivem, que as jovens deixem o campo.

A partir dos dados podemos observar o baixo nível de escolaridade, sendo que mais da metade tem ensino fundamental incompleto, na seqüência com 13\% do total de mulheres estão as que não sabem ler e nem escrever, embora esse percentual seja menor que o dos homens. Quando observamos as que possuem nível médio técnico, o percentual geral é de 
menos de $1 \%$, pois esse nível de estudo é destinado aos homens, assim como a formação superior. Estes dados permitem realizarmos uma reflexão sobre as diferenças existentes entre homens e mulheres no acesso a educação escolar e principalmente na autonomia da direção dos estabelecimentos. O trabalho da mulher é considerado como acessório ao do homem, embora muitas atividades como, por exemplo, a do leite fica sobre a responsabilidade das mulheres.

Tabela 01 - Percentual de estabelecimentos dirigidos por mulheres segundo faixa etária e grau de instrução no sudoeste paranaense

\begin{tabular}{|c|c|c|c|c|c|c|}
\hline & $\begin{array}{c}\text { menor } \\
\text { de } 25 \\
\text { anos }\end{array}$ & $\begin{array}{l}\text { De } 25 \text { a } \\
\text { menos de } \\
35\end{array}$ & $\begin{array}{c}35 \text { a } \\
\text { menos de } \\
45\end{array}$ & $\begin{array}{c}45 \text { a } \\
\text { menos de } \\
55\end{array}$ & $\begin{array}{c}\text { de } 55 \text { a } \\
\text { menos de } \\
65\end{array}$ & $\begin{array}{l}\text { de } 65 \text { a } \\
\text { mais }\end{array}$ \\
\hline $\begin{array}{l}\text { Alfabetização } \\
\text { de adultos }\end{array}$ & 0 & 0,01 & 0,05 & 0,09 & 0,14 & 0,15 \\
\hline $\begin{array}{l}\text { Ensino } \\
\text { fundamental } \\
\text { incompleto }\end{array}$ & 0,05 & 0,34 & 0,87 & 1,31 & 1,21 & 0,99 \\
\hline $\begin{array}{l}\text { Ensino } \\
\text { fundamental } \\
\text { completo }\end{array}$ & 0,03 & 0,13 & 0,19 & 0,22 & 0,1 & 0,08 \\
\hline $\begin{array}{l}\text { Ensino médio } \\
\text { (técnico } \\
\text { agrícola) }\end{array}$ & 0 & 0,02 & 0,02 & 0,02 & 0,01 & 0 \\
\hline $\begin{array}{l}\text { Ensino médio } \\
\text { (outro) }\end{array}$ & 0,05 & 0,12 & 0,16 & 0,14 & 0,07 & 0,01 \\
\hline $\begin{array}{l}\text { Formação } \\
\text { superior }\end{array}$ & 0 & 0,05 & 0,06 & 0,07 & 0,02 & 0 \\
\hline $\begin{array}{l}\text { Nenhum, } \\
\text { mas sabe ler } \\
\text { e escrever }\end{array}$ & - & 0,03 & 0,07 & 0,14 & 0,18 & 0,2 \\
\hline $\begin{array}{l}\text { Não sabe ler } \\
\text { e escrever }\end{array}$ & 0 & 0,01 & 0,06 & 0,19 & 0,33 & 0,56 \\
\hline Total & 0,13 & 0,71 & 1,48 & 2,18 & 2,06 & 1,99 \\
\hline
\end{tabular}

Fonte: IBGE. Censo agropecuário 2007.

A exclusão das mulheres nos processos formativos, escolares ou não, se constitui em um impedimento ou uma dificuldade na formação de quadros de lideranças que administram as entidades, os partidos, os sindicatos, enfim espaços públicos. São nestes espaços que se constroem e se absorvem as concepções políticas e os instrumentos de 
administração de gestão do trabalho, nele é que estão as possibilidades de se ampliarem os conhecimentos e com eles os horizontes.

As mulheres rurais participam desses eventos (reuniões, seminários, oficinas de trabalho) e dos próprios Conselhos, em número muito menor que os homens, e via de regra, quando se envolvem em alguma atividade concreta, o fazem especificamente nos temas ditos "sociais" (tais como saúde e educação) e em intensidade muito menor, nas atividades ditas “econômicas” (ligadas com a produção agrícola ou pecuária, e com a comercialização dos produtos). Neste último caso, sua inserção também se dá em atividades bem segmentadas, como a transformação de produtos (agroindústrias caseiras), serviços (turismo rural) ou atividades hortícolas (SILIPRANDI, 2010).

A agricultura familiar apesar de relegada, a um segundo plano durante décadas, tem ganhado relevância no debate acadêmico e na sociedade brasileira de forma geral nos últimos anos, sendo reconhecida como a principal responsável pela produção de alimentos e diversidade. No entanto, o reconhecimento desta não tem garantido as mesmas condições de equidade com uma outra estrutura de agricultura priorizada, especialmente pelas políticas públicas, desde a década de 1950, a chamada agricultura moderna destinada especialmente aos grandes estabelecimentos agropecuários. Assim a existência da agricultura familiar, praticada tem sido constantemente remetida a um processo de luta e resistência, incitando sua organização.

Essa organização social dos pequenos agricultores familiares no sudoeste do Paraná está posta desde a sua colonização e muitas foram e são as lutas que essa categoria de trabalhadores tem realizado para garantir sua permanência no campo. Segundo Batistti (2006), o sudoeste do Paraná foi projetado nacionalmente como um campo de disputa pela peculiaridade de seu padrão de colonização e organização produtiva e também por ser um espaço de disputa entre projetos governamentais e empresariais que se figuraram na revolta de 1957 e, mais recentemente, na estruturação a partir do pacote tecnológico da revolução verde.

São essas circunstancias territoriais, segundo o autor, que permitiram que os agricultores familiares descobrissem que a sua permanência na terra dependia de seu poder de organização política e econômica. É desta feita que surgem dezenas de entidades representativas da organização dos agricultores familiares envolvendo cooperativas de produção, comercialização, crédito, organização sindical, assistência técnica etc. 
O processo no qual se institui estas lutas é composto por homens e mulheres, no entanto a maioria, das entidades representativas é liderada por homens e a participação das mulheres, no âmbito público, fica muitas vezes relegadas à cota de 30\% destinadas por muitas instituições, porém no geral, as mulheres não ocupam os cargos de direção destas organizações.

Quando observamos a história da organização das mulheres agricultoras no sudoeste do Paraná, reconhecida pela sua capacidade organizativa, verificamos que o direito destas se filiarem ao sindicato do trabalhador rural ocorria após a morte do seu cônjuge. No entanto, estas participavam ativamente das bases materiais de construção da luta pela permanência e resistência da agricultura familiar. Um exemplo é no período da Revolta dos Posseiros, em 1957, quando muitas mulheres, em especial agricultoras, permanecem sozinhas em suas casas protegendo-as e aos seus filhos das perversidades dos jagunços, enquanto os homens se reúnem na cidade para também enfrentar as empresas colonizadoras e seus jagunços, garantindo a posse da terra. Mas a participação das mulheres nesta história é praticamente esquecida na sua oficialização.

A permanência dessas características e situações em que as mulheres são subsumidas permanecem e demonstram a dificuldade que as mulheres agricultoras tem enfrentado para continuar no campo e poderem participar dos seus processos organizativos. No entanto, na região, a participação política das mulheres, embora seja ainda muito pequena, tem feito parte constantemente da história destas. A invisibilidade não é por estas negligenciadas.

\section{A ORGANIZAÇÃO DAS MULHERES AGRICULTORAS}

No sudoeste do Paraná existiram dois fortes movimentos de organização das mulheres, em especial as agricultoras. O primeiro se inicia na década de 1970, denominado de Movimento Popular de Mulheres e o segundo em meados da década de 1980 a partir da organização sindical de base da CUT. Trata-se de organizações cuja centralidade não se constitui no fato de ser mulher, mas acompanha a estrutura territorial da região (política, econômica e cultural), baseando se na estrutura familiar, conforme aponta Santos (2008), a qual dá identidade ao território do sudoeste do Paraná. 
A ORGANIZAÇÃO DAS AGRICULTORAS: O MOVIMENTO POPULAR DE MULHERES AGRICULTORAS E O SINDICATO DE TRABALHADORES RURAIS

O Movimento Popular de Mulheres se constitui na região sudoeste do Paraná atrelado a Igreja Católica e sob forte influência das orientações de padres e leigos belgas que vieram para região na década de 1960, realizando um trabalho de evangelização e conscientização da organização produtiva dos agricultores familiares e reflexão sobre a importância do associativismo. “Os missionários belgas tentavam introduzir na região a Doutrina Social da Igreja e a dinamização dos movimentos leigos, reunindo grupos específicos (juventude, casais), numa linha de maior participação dos cristãos na discussão política e social que se desenrolava no resto do Brasil” (FERES, S/D, p.534).

Esse grupo tem como foco a organização dos agricultores e o seu despertar para uma ação mais politizada dos fiéis para permanência e resistência no campo, a partir das experiências vividas na Bélgica focam o debate no sindicato e na cooperativa. Estas ações foram à base de fundamentação das diversas formas de organização cooperativas que existem no sudoeste, assim como a presença de sindicatos de trabalhadores rurais, considerados combativos.

O Concilio Vaticano II foi à fonte mais imediata de inspiração pastoral dos padres belgas. Em 1963 era iniciado o movimento de Catequese Familiar, numa tendência de envolver mais adultos na educação religiosa dos filhos e, ao mesmo tempo, na sua auto-educação. Em 1964 fundava-se a Juventude Agrária Católica (o braço rural do movimento de jovens católicos). Em 1968 surgiram grupos de Reflexão, grupos fixos de adultos, com reuniões regulares em torno de temas ligados à vida familiar, ao trabalho e à situação geral da sociedade, baseados na leitura e comentário da Bíblia. Finalmente em 1971, eram criados os cursos de ministros leigos da Eucaristia (FERES, S/D, p.534).

Os missionários belgas envolvem em seus trabalhos religiosos, segundo Feres, principalmente homens, pois a Igreja Católica brasileira tradicional foca este trabalho nas mulheres. Pretendiam assim envolver a família neste processo de formação religiosa e também político. É neste contexto que em 1964 é criada a Associação de Estudos, Orientação e Assistência Rural (ASSESOAR), inclusive com apoio financeiro de grupos ligados à democracia cristã belga. Esta tinha o papel de assessoramento das práticas pastorais, de organização dos agricultores e reflexões da realidade: “(...) a falta de terra para os jovens, as condições desvantajosas de comercialização da produção regional, a pouca 
eficiência dos serviços do Estado na região, o marasmo político da população” (FERES, p.535).

O trabalho desenvolvido, especialmente por intermédio da ASSESOAR, atinge todo o sudoeste do Paraná e os agricultores e agricultoras são envolvidos na ampliação da participação política, sendo desde contexto que surgem os primeiros sindicatos de trabalhadores rurais na região, os quais, no entanto seguem a perspectiva assistencialista que predomina no sindicalismo brasileiro em um contexto de ditadura militar.

Ainda segundo Feres, a constituição desses sindicatos assistencialistas que iam de encontro às reflexões, colocam a ASSESOAR e parte das lideranças constituída neste processo em oposição a essa forma de organização e também a ditadura militar, assumindo uma posição política explicita, embora ensejam em si várias contradições, deixando aos poucos seu caráter pastoral. É a partir das práticas vivenciadas e potencializadas pelo trabalho desempenhado pela ASSESOAR que são constituídas iniciativa de resistência, tanto dos camponeses, como outras formas de associação dos agricultores.

O Movimento Popular de Mulheres que nasce no sudoeste do Paraná em 1970, é fruto desde processo, que embora não tenha uma ligação tão estreita com o Movimento Popular de Mulheres em nível de Brasil, principalmente na luta contra a ditadura, pois no sudoeste do Paraná a ação de repressão deste é expressiva, atua trazendo á reflexão centenas de mulheres que participam do mesmo. No entanto, como já destacamos anteriormente a sua base não fica restrita a luta feminista.

A formação que tínhamos para ser ministros, ajudou a entender o que estava na verdade por trás da ditadura militar (C.P. Agricultura - Francisco Beltrão, NARRATIVA, 2009).

Me formei ministra no trabalho da Assesoar em 1979 e a partir desta formação, formei então uma visão de libertação, militância e de buscar as lutas” (I. F. Educadora - Francisco Beltrão, NARRATIVA, 2009).

A organização das mulheres em torno dos grupos de reflexão de base possibilita que as mulheres do sudoeste do Paraná se indignem com os problemas sociais que afligem a agricultura familiar, como o baixo preço pago aos produtos agrícolas e estas se articulam na construção de um movimento local, mas que dialoga com outros espaços.

É desta consciência que surge a necessidade das mulheres agricultoras se organizar e participar ativamente dos sindicatos. Também tomo vulto às lutas por direitos sociais as 
mulheres agricultoras como a seguridade social, remuneração da licença maternidade, aposentadoria etc.

Na pesquisa com mulheres que participam desde movimento no sudoeste do Paraná, elas demonstram que naquele período tinham consciência do processo de luta que participavam, tendo apoio naquele momento da ASSESOAR e também da Igreja, principalmente em Capanema onde surgi o movimento. “A gente primeiro se organizou como mulher, depois as lutas sociais, e fomo(sic) à luta. Foi muito forte tivemos muitas conquistas em Capanema” (D.S. Capanema, NARRATIVA, 2009).

Desde a década de 1970, o Movimento Popular de mulheres no sudoeste do Paraná reúne suas participantes para estudar e debater temas como: Mulher e Política, Mulher e Bíblia, Saúde da Mulher entre outros objetivando que estas se reconhecessem e se valorizassem no processo de luta pela dignidade. Há uma organização local, mas também o dialogo a nível regional e também estadual, principalmente em relação à organização do dia internacional da mulher. "Nestes encontros se trabalhava o que estava em destaque no ano, por exemplo, política, constituinte, o salário maternidade, dependia da necessidade do momento” (S.W. Capanema, NARRATIVA, 2009).

Os dados levantados em documentos e entrevista mostram que esse movimento permanece no sudoeste do Paraná por cerca de 20 anos, durante sua existência trata de temas ligados à emancipação das mulheres e isto provoca muitos conflitos, em especial em relação às concepções de cunho religiosas, como aborto, emancipação da mulher, questões de gênero etc.

Apesar da existência de dialogo entre as mulheres que participavam do movimento popular de mulheres no sudoeste com as de outras regiões havia muitas especificidades na organização desde em cada região. É como salientamos no sudoeste centrava-se mais na família agrícola, enquanto em outras se pautava em uma discussão de gênero, enquanto relações sociais de poder. Mas de qualquer forma, a participação da Igreja, em especial a Católica, a partir da Teologia da Libertação contribui para que essas mulheres e homens comecem a se sentir incomodados com muitas praticas assistencialista e de exploração aos quais estavam submetidos. 
A participação das mulheres agricultoras contribue para que essas saiam dos espaços privados de suas casas e assumam espaços públicos, geralmente destinados aos homens. É neste contexto que esse grupo se aproxima da organização sindical, lutando inclusive para que a filiação ao sindicato não ocorresse somente no nome do marido.

Uma vez que os sindicatos eram a principal fonte de assistência à saúde em áreas rurais, a exclusão de mulheres dos sindicatos significava que as mulheres chefes de família estavam em forte desvantagem. As mulheres também estavam em desvantagem em termos de benefícios de aposentadoria, já que somente uma pessoa por família era qualificada para tais benefícios, o chefe de família. Além disso, considerando que os trabalhadores recebiam $50 \%$ do salário mínimo na aposentadoria, suas viúvas recebiam uma pensão de sobrevivente, o equivalente a 30\%. (...) (DEERE, 2004, p.180).

Assim, no sudoeste do Paraná o Movimento Popular de Mulheres contribui para a constituição de sindicatos combativos, conseguindo realizar um forte debate a partir de suas ações na região, no entanto quando da conquista desse sindicato e da criação de uma comissão sindical específica de mulheres, há um recuo do primeiro e duas formas de organizações focadas nas mulheres passam a existir, embora em alguns momentos trabalhos são realizados conjuntamente e as mulheres de um movimento participavam do outro.

Esta divisão se dava porque havia duas concepções na organização de mulheres uma do Movimento popular de Mulheres que enfocava os direitos humanos desde a religião, na perspectiva do feminismo e outra da Comissão Sindical que focava no direito social enquanto trabalhadoras rurais” (C.R.P, Francisco Beltrão, NARRATIVA, 2009).

É importante destacar que não é a constituição da Comissão Sindical que desestrutura o Movimento Popular de Mulheres e sim o retraimento da ala progressista católica no final da década de 1980.

Segundo a Deere (2004), em 1985, ocorre o primeiro congresso da CONTAG com uma inclusão de pauta específica, apesar do pequeno número de agricultoras presente esse foi um momento de conquista de suas reivindicações.

Embora as mulheres representassem somente 1\% dos participantes nesse congresso nacional, a CONTAG adotou o objetivo de incorporar as mulheres dentro da estrutura do sindicato e reconheceu que elas passam por problemas específicos de discriminação, principalmente a discriminação nos salários. Os sindicatos municipais foram instruídos a encorajar a participação de mulheres e treiná-las para ocuparem posições de liderança. Elas também foram encorajadas a eleger mulheres como delegadas para congressos estaduais e nacionais. A necessidade de mulheres rurais, especialmente aquelas em regime de agricultura familiar, declararem que sua profissão era de mulher trabalhadora rural também foi discutida, tanto como meio de levantar sua consciência, como para facilitar sua incorporação nos sindicatos e ter acesso a benefícios de previdência social. 
Essa medida reflete a organização das mulheres, mas também a disputa sindical que se instituía, contra a forma assistencialista de sindicalismo e pela criação da Central Única dos Trabalhadores (CUT). A participação das mulheres representava esse processo de mudança no sindicalismo.

Segundo dados da pesquisa realizada, o Sindicato de Trabalhadores Rurais de Francisco Beltrão, foi um dos pioneiros na organização de mulheres a nível de região sul na década de 1980, mais tarde mulheres de outros estados e municípios de Paraná participam desta luta. Em 1981, o sindicato de Francisco Beltrão conta com a participação de mulheres e inicia uma campanha de filiação destas.

As mulheres entrevistadas na pesquisa afirmam que havia uma estratégia de realização das reuniões para que toda a família pudesse participar e não se debatia tema específico da mulher e sim da família. A filiação passava a ocorrer em nome do marido e da mulher, cada qual contribuindo com 50\% do valor da taxa de filiação, garantindo assim também seu direito ao voto e a ser votada. A temática inicial foi sobre o direito à previdência social, pois na época os homens (trabalhadores rurais) recebiam meio salário de aposentadoria a partir dos 65 anos e as mulheres não recebiam nada, segundo as entrevistadas, os homens achavam justo que elas também recebessem tal valor, mas elas diziam que "não eram meia pessoa” e queriam receber o salário integral. Apesar da forma tímida, foi se ampliando a participação das mulheres no sindicato.

No sudoeste do Paraná, uma parcela significativa dos sindicatos tidos como combativos, era filiada a CUT, a qual se opunha ao trabalho que os sindicatos ligados a Federação de Trabalhadores na Agricultura do Estado do Paraná (FETAEP), filiados a Confederação Nacional de Trabalhadores na Agricultura (CONTAG). A participação das mulheres se amplia e em 1983, no município de Capanema, se constitui o primeiro sindicato combativo daquela localidade, com a participação das mulheres na executiva, as quais encontram muitas dificuldades na sua inserção.

Muitas tinham que mentir para a mãe, ou marido, pois não aceitavam sua participação no sindicato. (...). Em maio de 1983 comecei a participar no sindicato na oposição sindical. Imagina uma mulher solteira, tesoureira de um sindicato, o auê que deu na cidade. Assumi a direção em janeiro de 1984 (M.L.C, Capanema. NARRATIVA, 2009). 
Segundo DEERE (2004), em 1986, a CUT em seu segundo Congresso organiza a Comissão Nacional para tratar sobre a questão da mulher trabalhadora. Entre diversas participações e motivações destacamos a reivindicação da organização das mulheres trabalhadoras rurais do Rio Grande do Sul que exigiam que os direitos das mulheres fossem reconhecidos, com a inclusão dos seus nomes nos títulos das terras da reforma agrária e não somente em nome dos maridos, como era realizado. Reclamavam que sendo a família o critério utilizado para distribuição de terras, as mulheres deveriam ser reconhecidas independente de estado civil.

Como o trabalho das mulheres fica mais restrito ao âmbito da casa, do estabelecimento, embora signifique dupla jornada de trabalho, ele durante muito tempo não foi reconhecido como uma atividade profissional. Como relatado anteriormente, o homem era considerado oficialmente e no cotidiano o agricultor e a mulher sua ajudante, por isso não era reconhecida profissionalmente, não recebendo salário e nem tendo direito à aposentadoria. A existência dessa desigualdade reflete a divisão de trabalho por sexo, a qual submete as mulheres ao poder dos homens, sendo a questão tratada ou não como algo natural.

Essa situação se transforma em uma bandeira de luta, assumida pelas mulheres no sindicato, para convencimento político e também da mentalidade de muitas famílias que tinham a situação como natural. Para muitos (homens e mulheres), o que deveria mudar não era o reconhecimento da mulher como agricultora, mas sim a sua remuneração, em especial concernente à aposentadoria, mais uma vez demonstrando a submissão das mulheres nesta relação de poder da sociedade capitalista.

Assim a luta pelo salário da mulher, também se constitui em uma etapa da luta contra o patriarcado e a submissão das mulheres. Pois a existência da remuneração por si, não garante maior equidade nas relações entre homens e mulheres na organização da agricultura familiar. Mas na sociedade que valoriza o ter, esse reconhecimento é uma importante bandeira de luta.

A consciência das mulheres e a decisão de assumir a luta por intermédio do sindicato de trabalhadores rurais trouxeram a elas muitos desafios. Apesar da participação das mulheres nas direções sindicais, para muitos sindicatos tal efetivação ocorre a partir de 
1993, quando se cria a cota de no mínimo 30\% de mulheres nas direções dos sindicatos filiados a CUT, deliberando também aos seus sindicatos filiados:

As perguntas que se faziam na época eram: Como que as mulheres podem estar nas direções? Quais são os cargos que as mulheres estariam ocupando? Secretária? Limpeza das salas? Não foi culpa somente dos homens, muitas mulheres são lutavam pela conquista do espaço, pois tinham dificuldade de reconhecer sua capacidade principalmente pela sobrecarga de tarefas familiares (V. S. - Honório Serpa, NARRATIVA, 2009).

A participação das mulheres agricultoras apesar das adversidades, demonstra a compreensão da importância política no processo de organização dos trabalhadores rurais, assim como posteriormente dos partidos políticos. Como verificamos na pesquisa as dificuldades encontradas pelas mulheres na participação nas organizações políticas decorrem também das próprias mulheres que concebem como natural ficar em casa, outro motivo, segunda elas, que dificulta sua inserção política é a baixa escolaridade.

Mas outras temáticas envolvem a participação das mulheres, uma delas é a luta pela terra, que se constitui na pauta das organizações populares na década de 1980 e as mulheres envolvidas no sindicato, envolvem-se nessa luta. A maioria das mulheres que assumem as organizações faz parte das pastorais da Igreja, em especial, da ala progressista católica e assim como as resistências a sua participação, encontram apoio em vários homens que participam do sindicato ou de outras formas de organização popular. “Com o surgimento dos sindicatos combativos na região os próprios maridos começaram a chamar as mulheres para participar, abriram esse espaço, foram importantes” (S.G.Z., Renascença, NARRATIVA, 2009).

Havia uma efervescência política, local e nacional, com fortes oposições à organização popular e sindical, que necessitava da participação ativa de homens e mulheres para garantir a existência dessas organizações de trabalhadores. Assim, as temáticas específicas das mulheres não eram centrais e sim a destas enquanto trabalhadoras rurais. Estas assumem a luta em defesa da agricultura familiar. "Tanto no movimento sindical como quando iam às lutas do MST, passeatas e mobilizações, as mulheres iam a frente porque os policiais respeitavam, não batiam tanto” (I. F. , Francisco Beltrão. NARRATIVA, 2009).

A participação das mulheres, com sua entrada nos sindicatos possibilitam visibilidade a estas e, embora continuam enfrentando preconceitos, sua lutas e bandeiras 
ganham expressividade local e nacional. Mas são lutas sempre em torno do seu reconhecimento enquanto profissional da agricultura e por direitos sociais para si e para a família.

\section{CONSIDERAÇÕES}

[...] em 1992 fui candidata à vereadora pelo PT (radical) no município de Francisco Beltrão [...] Sempre falávamos que as mulheres precisavam participar nos campos social, econômico e político, porém havia preconceito em relação à mulher política, era muito forte a questão do machismo: porque a mulher se envolve em política, para quê? $\mathrm{O}$ fato de ser agricultora... uma coitada! Por mais que algumas não acreditassem, provou-se a importância da base, do grupo de mulheres, de mulher votar em mulher. Se não tivesse tido a confiança e o voto das mulheres não teria me elegido. Fui base para outras mulheres. A semente que germinou. A partir deste ano começou a crescer a participação das mulheres no movimento sindical. As mulheres agricultoras influenciavam as mulheres urbanas. Davam exemplo (L. R. - Francisco Beltrão. NARRATIVA, 2009).

No sudoeste do Paraná, a participação da agricultura na organização territorial ocupa um lugar e centralidade. É a partir dela que se constitui em principais movimentos de organização territorial como a Revolta dos Posseiros de 1957, a modernização da estrutura produtiva, a edificação de entidades representativas, o fomento a vida no campo e na cidade, o êxodo rural, entre outros. Segundo Santos (2008), é a agricultura familiar um elemento de identidade territorial do sudoeste do Paraná. Assim, este se constitui em um território em constante processo de metamorfoses, que vai sendo constituído a partir das relações que nele se estabelecem.

A organização das mulheres agricultoras familiares é, portanto, uma manifestação territorial que contribui para a constituição de um território que expressa seus conflitos, dentre eles o de gênero e geração, que marcam e demarcam este espaço, como as pequenas propriedades, a pobreza rural, o esvaziamento das funções exercidas pelas pequenas cidades, a subordinação do trabalhador às agroindústrias, diversificação industrial e das atividades de serviços em algumas cidades, uma organização patriarcal entre outros. Estes e outros elementos combinam-se e articulam os diferentes territórios que constitui o sudoeste do Paraná.

Nesta constituição verificamos a presença forte de relações de poder e aqui destacamos a agricultura familiar de cunho patriarcal, que em suas ações cotidianas 
domésticas ou nos espaços públicos restringem a participação das mulheres. Desse fato decorre, a existência de grande número de organizações representativas da agricultura familiar, mas, no entanto, a participação das mulheres na direção destas é pequena.

Vale destacar que as lutas efetivadas, especialmente pós 1988, consisti no reconhecimento da mulher como trabalhadora rural e pelo direito de filiação em sindicatos, cooperativas, partido político, mas também salário maternidade, aposentadoria, documentação particular. Essas bandeiras são alcançadas com a mobilização de muitos homens e mulheres que reconheciam nelas uma luta conjunta em defesa da agricultura familiar.

A família patriarcal é a base desta organização territorial, assim a conquistas de direitos não significa o rompimento com situações preconceituosas contra homens, mulheres e jovens que desafiam mudar esta estrutura. Quando se observa a masculização e o envelhecimento da população rural no sudoeste do Paraná, se tem um indicativo da territorialidade que se constitui a partir desta estrutura.

O território como o espaço constituído a partir das relações de poder que o constrói é, portanto, um conceito fundamental para entender a organização de mulheres em um território marcado pela identidade de uma agricultura familiar patriarcal. As análises que trazemos possibilita uma reflexão e uma provocação para se avançar neste estudo a partir de uma abordagem territorial. Essa meta não é atingida neste texto, mas demonstra um indicativo de estudos para aqueles que buscam a construção de uma geografia para homens e mulheres.

\section{REFERÊNCIAS}

BATISTTI, Elir. As disputas pela terra no sudoeste do Paraná: os conflitos fundiários dos anos 50 e 80 do século XX. Campo- Território: revista de geografia agrária, v.1, n.2, p. 6591, ago. 2006.

DEERE, Carmem Diana. Os direitos da mulher à terra e os movimentos sociais rurais na reforma agrária brasileira. IN: Rev. Estud. Fem. [online]. 2004, vol.12, n.1, pp. 175-204. acesso em 01/04/2010.

KNAPIK, Márcia Carneiro (org). Movimento Popular de Mulheres do Paraná: 10 Anos Construindo Vida.

NARRATIVA. Registrando a História e as Experiências Político-Organizativas das Mulheres Agricultoras No Sudoeste Paranaense. Unioeste, Francisco Beltrão, 2009. 
SANTOS, Roseli Alves dos. O processo de modernização da agricultura no sudoeste do Paraná (Tese de doutorado). Programa de Pós-graduação em Geografia. UNESP, Presidente Prudente, 2008.

SILIPRANDI, Emma. Mulheres rurais e políticas de desenvolvimento: considerações a partir da extensão rural. IN: www.nead.org.br/download.php?form=.pdf\&id=233, acessado em 02 de abril de 2010.

Enviado para publicação em dezembro de 2010.

Aceito para publicação em dezembro de 2010. 